\title{
Model Test and Theoretical Analysis of New and Old Embankments Differential Settlement Considering Lateral Deformation
}

\section{Gao-hang Lv}

Shandong University

Wei Cui

Shandong University

Shu Jian Wang (D 545293976@qq.com )

Shandong University

\section{Research Article}

Keywords: embankment, lateral deformation, model test, theoretical analysis

Posted Date: April 19th, 2021

DOI: https://doi.org/10.21203/rs.3.rs-433288/v1

License: (c) (i) This work is licensed under a Creative Commons Attribution 4.0 International License.

Read Full License

Version of Record: A version of this preprint was published at Geotechnical and Geological Engineering on May 31st, 2021. See the published version at https://doi.org/10.1007/s10706-021-01862-4. 


\title{
Model test and theoretical analysis of new and old embankments differential settlement considering lateral deformation
}

\author{
Gao-hang Lv ${ }^{1}$, Wei Cui, ${ }^{2}$ Shu-jian Wang ${ }^{1 *}$ \\ ${ }^{1}$ School of Civil Engineering, Shandong University, Jinan 250061, China. \\ ${ }^{2}$ Geotechnical \& Structural Engineering Research Center, Shandong University, Jinan \\ 250061, China.
}

Correspondence should be addressed to Shu-jian Wang; 545293976@qq.com

\begin{abstract}
In the embankment widening project, the new embankment will produce large deformation due to the low degree of consolidation, which will affect the stability of the embankment. Obtaining the settlement law of embankment is the premise to ensure the stability of the embankment. In this paper, the deformation law of the new embankment is studied through the embankment model test, and the settlement calculation method of the new embankment is proposed. The model test results show that the new and old embankments have a large settlement difference during the loading process, and the maximum settlement of the new embankment is twice that of the old embankment. The lateral deformation of the new embankment is directly proportional to the vertical deformation, sliding occurs under the ultimate load, and the bearing capacity is lost. Based on the one-dimensional calculation method, the lateral deformation coefficient is introduced, and the two-dimensional embankment settlement formula is obtained. The new embankment is meshed, and the deformation of each node is calculated by the formula, and the difference between the settlement and the model test data is $6.2 \%$, which proves the feasibility and accuracy of the calculation method.
\end{abstract}

Keywords embankment; lateral deformation; model test; theoretical analysis

\section{Introduction}

In the highway expansion project, the degree of consolidation of the new embankment is relatively low (Sun et al. 2011; Liu et al. 2015), the highway embankment will produce vertical deformation and lateral deformation under the action of pavement load, as a consequence, traffic safety will be affected and maintenance costs will increase (Sun et al. 2011; Liu et al. 2015). Related research shows that lateral deformation has an important influence on the stability of embankment(Liu et al. 2018; Cai et al. 2017; Li et al. 2008). In embankment engineering, most of the calculation methods and parameters are based on Terzaghi's one-dimensional consolidation theory. It is assumed that the deformation mechanism of the foundation soil is limited laterally and only produces vertical settlement, which is inconsistent with the actual situation (Reshma et al. 2020; Wu et al. 2020).

Embankment treatment form, soil layer structure, and height are important factors affecting the lateral deformation of the embankment(Fang et al. 2005). Tavernas summarized the laws of lateral and vertical deformation of 21 different embankments and analyzed the internal relationship between the lateral and vertical deformation of embankments(Tavenas et al. 1979). Indraratna monitors the lateral and vertical deformation of the embankment through 
two full-scale filling tests on-site, and finds that there is a corresponding relationship between the two deformations(Indraratna et al. 1997). A full-scale on-site embankment filling test was carried out to compare and analyze the lateral deformation law of the natural foundation and CFG pile-net composite foundation under the embankment load. (Pan et al. 2020). After experimental research, it is concluded that there is a corresponding relationship between the lateral deformation of the embankment and the vertical deformation. How to use the theoretical formula to analyze the relationship between transverse and longitudinal deformation is the key to further analyze the law of lateral deformation of the embankment. In theory, Loganathan proposed a field deformation analysis method to analyze the vertical and horizontal deformation characteristics of soft foundations(Loganathan et al. 1993). Han found that the settlement caused by the lateral displacement of soft soil foundation accounts for about $20 \%$ of the total settlement through the equal volume method embankment lateral displacement settlement model (Han et al. 2012). Considering the reaction of the foundation, Jiang established the unified coordinate system of embankment slope and aspect ratio by using the Boussinesq equation and deduced the solution method of embankment lateral deformation under equivalent trapezoidal load(Jiang et al. 2014). Giroud studied the initial settlement caused by the lateral deformation of Embankment under trapezoidal load such as embankment when the depth of the compressible layer foundation is constant (Giroud et al. 2012).

Most of the above studies focused on the analysis of the lateral deformation of the existing embankment and did not analyze the law of embankment deformation when the new and old embankment overlapped. Due to the difference of consolidation degree between old and new embankments, this will affect the deformation law of new embankments. In the highway expansion project, how to reasonably analyze the vertical and lateral deformation of the new embankment has important engineering significance. In this paper, aiming at the overlapping problem between the old and the new embankment, the embankment model test device is developed. Through the model test, the deformation law of the new embankment and the relationship between the settlement and lateral deformation is obtained. On this basis, the lateral deformation parameters are introduced and the one-dimensional calculation method is combined to derive the two-dimensional settlement calculation formula of the new embankment, which improves the accuracy of embankment settlement calculation. It provides a reference for the design and construction of the highway embankment expansion project.

\section{Test principle and device}

\subsection{Setting the model test size}

In the highway expansion project, the width of the existing embankment is $26 \mathrm{~m}$, the width of the integral embankment after the expansion of the eight lanes is $42 \mathrm{~m}$, and each side of the width is $8 \mathrm{~m}$. According to the principle of the symmetry of the structure, one side of the structure is selected for the simulation.

According to the scale requirements of geometric similarity in the geomechanical model test, the dimensions of each component of the model test should be proportional to the actual embankment structure. The length, width, and height of the test stand are $(1.5 \times 1.5 \times 1.5 \mathrm{~m})$. According to the principle of the similarity ratio, the geometric scale $C_{L}=13.33$. The new and old embankments in the model are spliced using the step method, so the model step is simplified because the size of the model test is smaller than that of the prototype; it is 
difficult for it to be the same size as that of the prototype. From top to bottom, the height of the upper two steps is $0.15 \mathrm{~m}$, and the last step is $0.2 \mathrm{~m}$. The width is $1.5 \mathrm{~m}$ and the slope ratio is $1: 1$. The specific dimensions are shown in Fig. 1.

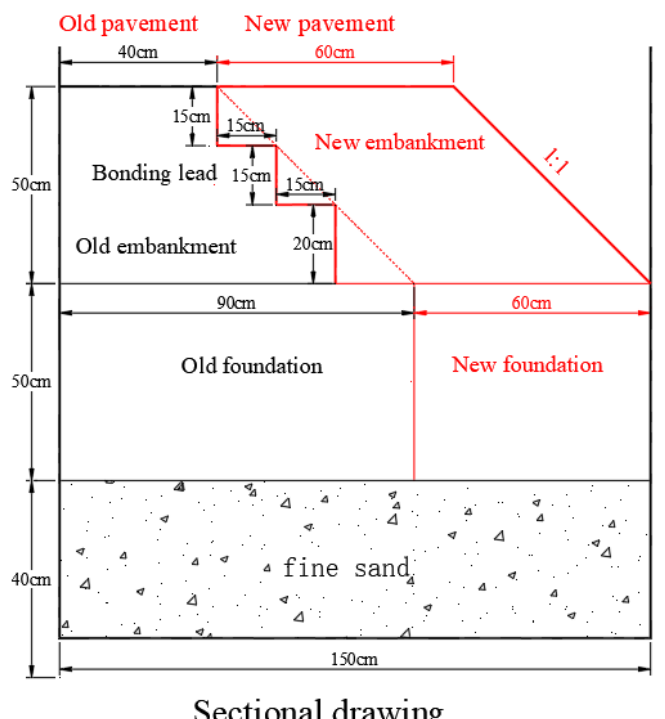

Fig. 1 Model size chart.

\subsection{Model test stand}

The test frame is mainly composed of three parts: reaction frame, hydraulic roof, and packing box. The hydraulic roof is controlled by a servo motor, the maximum load is 20t, which can achieve graded loading, and the minimum loading step is $0.1 \mathrm{kN}$. The test stand is shown in Fig. 3a. To apply a uniform load, a special loading device is designed (Fig. 2b), which can load the pavement load without affecting the differential deformation.
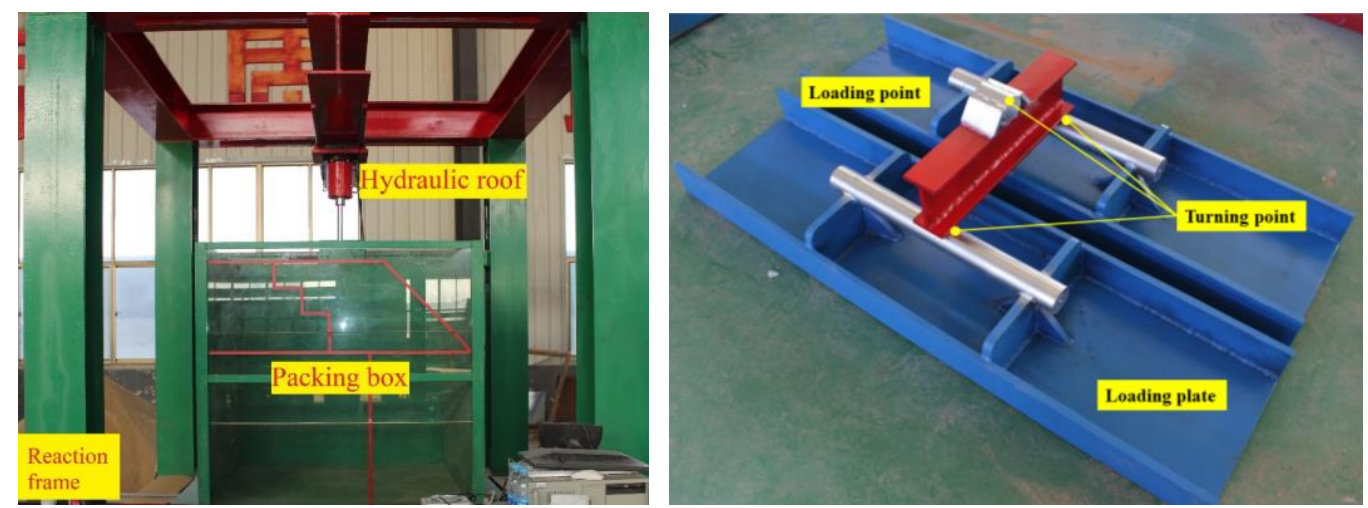

Fig. 2 The test device. (a) Test stand. (b) Road loading device.

\subsection{Model test material}

The model material is the embankment soil of Changsha Shenzhen highway. The basic parameters of the soil samples are shown in Table $\mathbf{1 .}$ 
Table 1 Material parameters.

\begin{tabular}{cccccc}
\hline \multirow{2}{*}{ position } & Soil type & Clay content $\left(P_{\mathrm{c}} / \%\right)$ & $\begin{array}{c}\text { SPT } \\
\text { Hammer number } \\
(N)\end{array}$ & $\begin{array}{c}\text { Liquidity } \\
\text { index }\left(\mathrm{I}_{1 \mathrm{E}}\right)\end{array}$ & $\begin{array}{c}\text { Threshold } \\
\mathrm{N}_{\mathrm{cr}} \\
d_{\mathrm{s}} \leq 15\end{array}$ \\
\hline K53+724.0 & silty soil & 9.5 & 5 & 1.3 & 5.3 \\
\hline
\end{tabular}

\subsection{Sensor type and arrangement}

The main purpose of the model test is to analyze the law of differential settlement of new and old embankments. The displacement sensor is used to monitor the layered deformation of the embankment and the lateral deformation of the slope. The earth pressure inside the embankment is measured by the earth pressure sensor, and the load transfer law is analyzed. The sensor location is shown in Fig. 3. The resistive displacement sensor is the model JTMY7000 displacement sensor with a range of $0-50 \mathrm{~mm}$, output sensitivity coefficient of 500 $1000 \mathrm{~d}(\mu \varepsilon / \mathrm{mm})$, and measurement accuracy of $0.1 \mathrm{~mm}$. The JTM-Y2000 miniature soil pressure sensor is used, the outer diameter is $16 \mathrm{~mm}$, the thickness is $4.8 \mathrm{~mm}$, the measuring range is $0.02-20 \mathrm{MPa}$, and the output sensitivity coefficient is $1000-30(\mu \varepsilon / \mathrm{MPa})$.
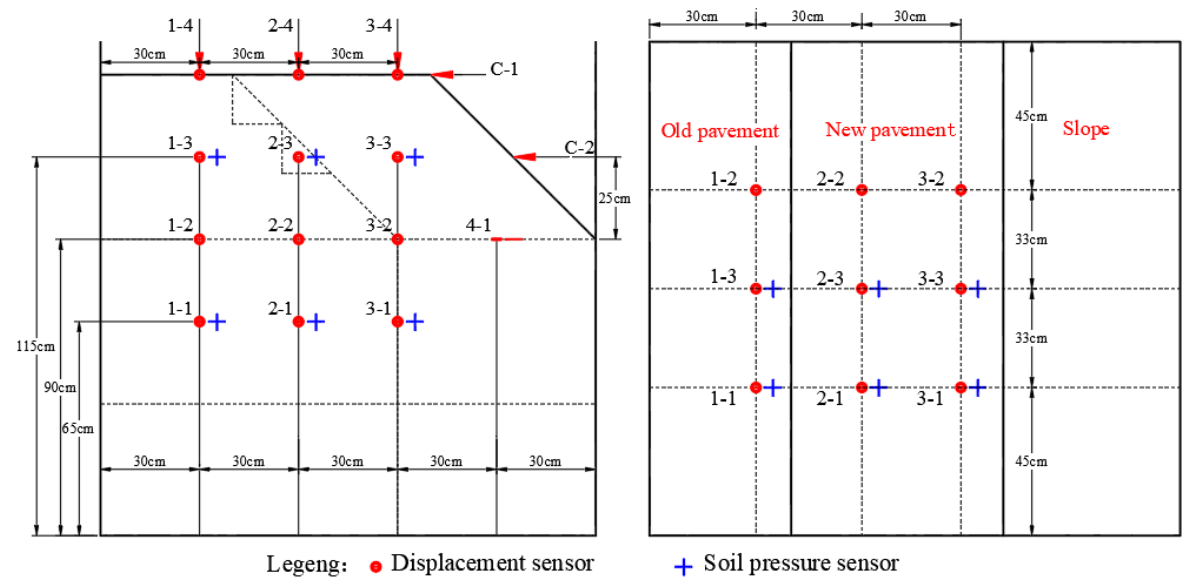

Fig. 3 Monitoring point layout.

\subsection{Data acquisition device}

Model testing requires a multi-channel instrument for data acquisition. The DH3816n static strain data acquisition instrument is selected. The collector has 60 channels that can collect data, such as displacement, stress, and loading force. The sampling frequency is $1 \mathrm{~Hz}$. The collector is connected to a computer through a network cable to automatically collect data and store it.

\section{Test process and results}

\subsection{Installation of the sensor}

\section{(1) Internal displacement sensor and pressure sensor}

The position of the fixed bearing on the displacement sensor is fixed and the direction is vertical during the sand filling process. After the fine sand is layered and compacted, a layer 
of geogrid is placed on top to separate the fine sand and fill so that multiple tests can be conducted.

\section{(2) Surface displacement sensor}

After the steps of the old embankment are built, the new embankment should be filled. The new embankment is still filled based on the previous filling method. The compactness of the fill is measured in layers during the compaction process.

There are five monitoring points for the road surface and slope deformation. Test loading uses the step-by-step loading method, the next level of loading does not start until the displacement changes begin to stabilize after the loading, and the increment of each step is $2 \mathrm{kN}$. Loading stops when the embankment model shows significant damage.

\subsection{Splicing test results for the new and old embankments}

The monitoring data for the settlement at different locations in the model test for the new and old embankments are shown in Fig.s 4-5.

Fig. 4 shows the settlement of different parts of the model test embankment. As shown in Fig. 4 , the settlement of new embankment and pavement reaches $17.9 \mathrm{~mm}$, and the maximum settlement of the old embankment is $7.7 \mathrm{~mm}$, the final settlement of the new embankment is twice that of the old embankment, and the differential settlement of the embankment is large. Compared with the surface of the embankment, the difference of the internal settlement of the embankment is relatively small. That the settlement of the embankment is mainly concentrated in its upper layer.

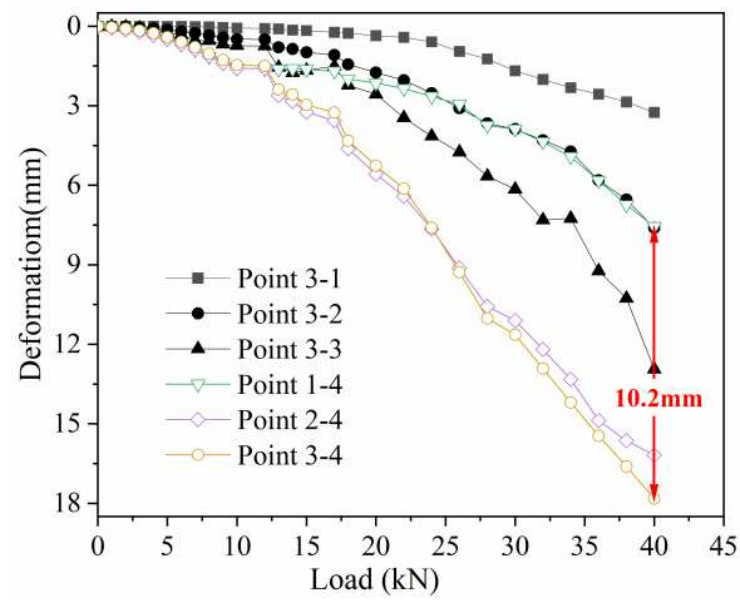

Fig. 4 Settlement of the embankment.

Fig. 5 shows the lateral deformation of the embankment slope. The lateral deformation of the embankment is low at the initial stage of loading. When the load increases to $15 \mathrm{kN}$, a large inflection point appears at the top of the slope, and the lateral deformation is large. By the time the load is $32 \mathrm{kN}$, there is a significant lateral deformation at the position of the slope, and the embankment is plastically damaged under this load condition. Fig. 5 shows that lateral deformation does not exist for the embankment slope when the load is small. When the load increases to a certain value, the lateral pressure generated by the vertical settlement of the embankment is greater than the lateral resistance provided by the embankment slope. 
Then the slope begins to be damaged and the bearing capacity is reduced.

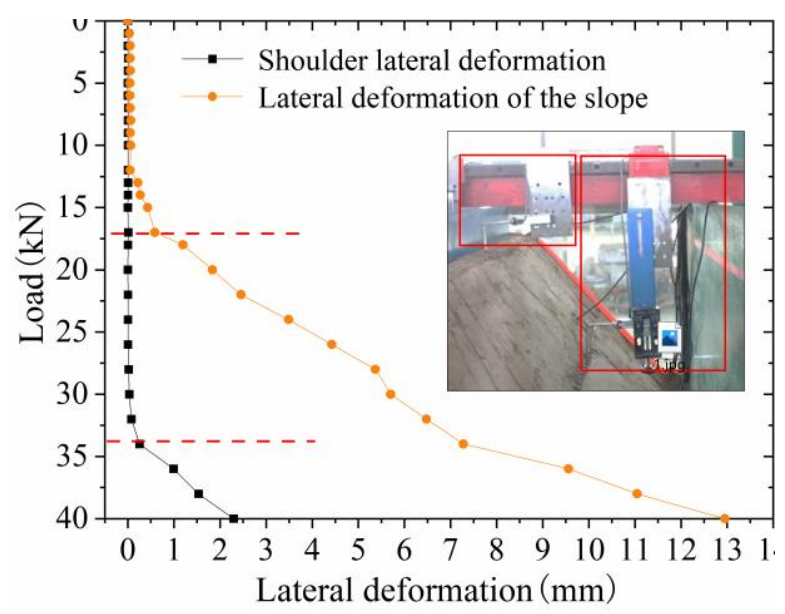

Fig. 5 Lateral deformation.

Fig. 6 shows that the shear failure surface of the embankment slope is visible, which is also the main reason for the lateral deformation of the slope. When such shear failure occurs on the embankment slope, the bearing capacity has been lost in the embankment.

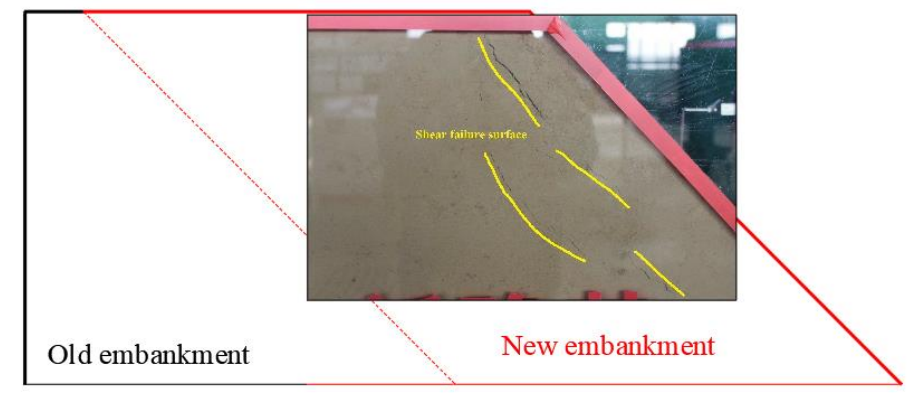

Fig. 6 The failure mode of the new embankment.

\section{Settlement calculation considering lateral deformation}

\subsection{Principle of the calculation}

In embankment engineering, the layered summation method is often used to calculate embankment settlement. Settlement $\Delta \mathrm{S}$ is calculated as Equation 1:

$$
\Delta S=\frac{e_{1}-e_{2}}{1+e_{1}} L
$$

where $\mathrm{e}_{1}$ is the initial void ratio, $\mathrm{e}_{2}$ is the compressed void ratio, and $\mathrm{L}$ is the layered width $/ \mathrm{m}$.

Fig. 7 shows that the settlement and lateral deformation of the embankment have the same law, that the lateral deformation is related to the settlement, but the traditional calculation method ignores the effect of the new embankment slope, which has a great impact on the calculation results. Therefore, combined with the calculation method for passive earth pressure, the effect of this part of the earth pressure on embankment settlement is weighted to 
correct the calculation results in the settlement calculation for the embankment. The action of the embankment slope is applied to the embankment soil unit in the form of passive earth pressure.

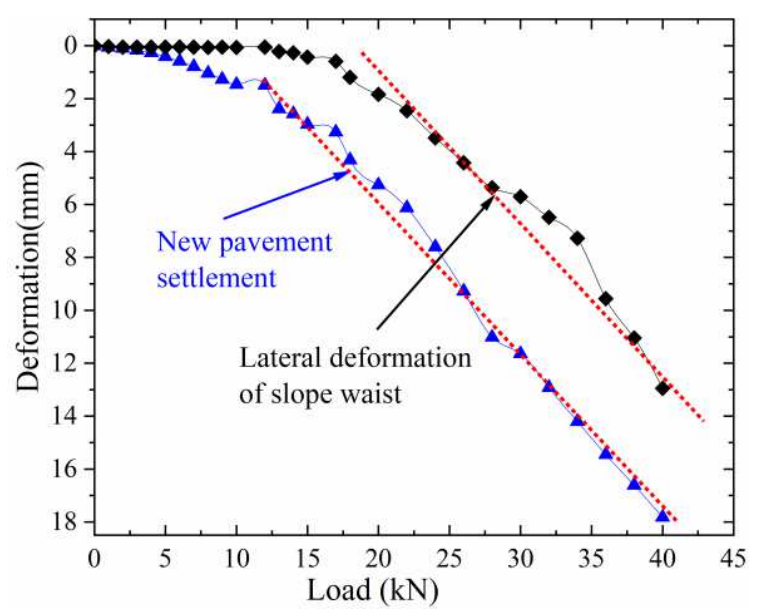

Fig. 7 The deformation relation.

The stress model of soil is shown in Fig. 8(a). The unidirectional deformation model of soil is shown in Fig. 8(b). The vertical deformation of the soil is $\Delta S$ and the two-way force deformation model of the soil is shown in Fig. 8(c), the vertical deformation is affected by the lateral pressure, and the new vertical deformation is $\Delta \mathrm{S}^{\prime}$. Therefore, the vertical deformation of the two calculated models produces the difference $S$, hence, how to calculate $\mathrm{S}^{\prime}$ is the key to the problem.

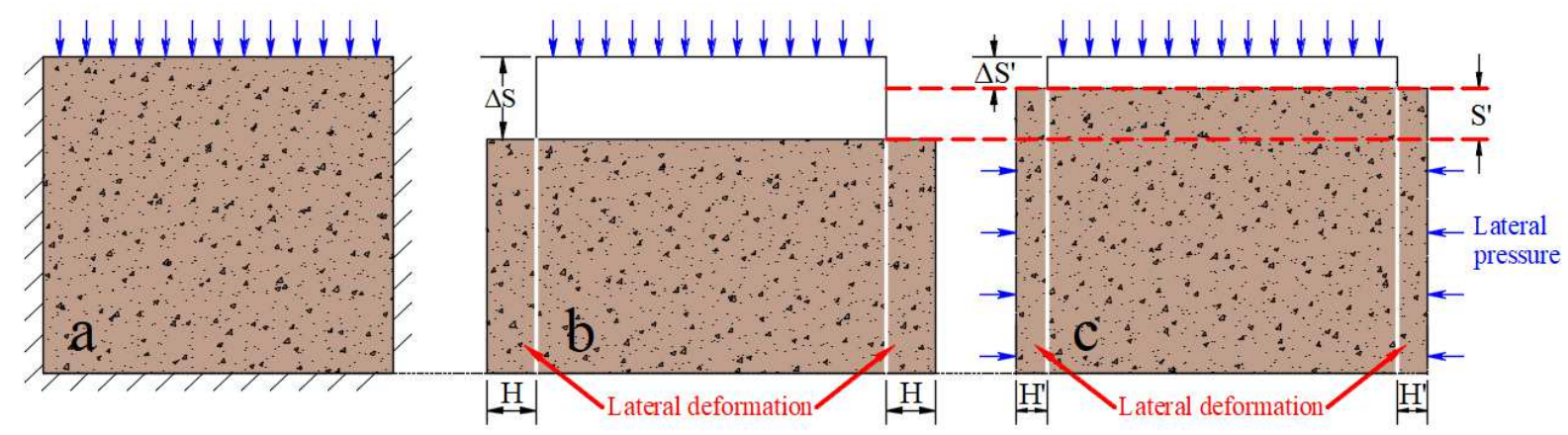

Fig. 8 Calculation model. (a) soil unit. (b) No lateral pressure deformation. (c) With lateral pressure deformation.

Regarding the theoretical lateral deformation of the embankment, calculated the ratio of the lateral displacement $\Delta \mathrm{L}_{\mathrm{m}}$ and the embankment to the central settlement $\Delta \mathrm{S}_{0}$ through the correction of the field test results based on the research conclusions of Tavena [Ma, 1995]. Ma proposed that the lateral displacement in the early stage of construction is quite small, and the ratio of the lateral displacement to the central settlement during the late stage of construction is $\left[\Delta \mathrm{L}_{\mathrm{m}} / \Delta \mathrm{S}_{0}\right](0.07 \sim 0.30)$, where the ratio is expressed as $\mathrm{K}_{\mathrm{n}}$.

Using backward deduction through the relationship between lateral displacement and central settlement, if the lateral displacement is calculated, the magnitude of its vertical displacement can be determined. According to this theory, the passive earth pressure generated by the embankment slope is used as the load, and the lateral deformation is calculated using the 
stratified total settlement method. The vertical deformation difference $S^{\prime}$ is calculated as Equation 2:

$$
S^{\prime}=K_{n} v \frac{e_{1}^{\mathrm{H}}-e_{2}^{\mathrm{H}}}{1+e_{2}^{\mathrm{H}}} H
$$

where $v$ is the soil Poisson's ratio, $\mathrm{K}_{\mathrm{n}}$ is the loss coefficient, $e_{1}^{\mathrm{H}}$ is the lateral initial void ratio, $e_{2}^{\mathrm{H}}$ is the laterally compressed void ratio, and $\mathrm{H}$ is the lateral layered width/m.

After correction, the settlement calculation formula of a pavement point is as Equation 3:

$$
\Delta S^{\prime}=\Delta \mathrm{S}-S^{\prime}=\frac{e_{1}-e_{2}}{1+e_{1}} L-K_{\mathrm{n}} v \frac{e_{1}^{\mathrm{H}}-e_{2}^{\mathrm{H}}}{1+e_{2}^{\mathrm{H}}} H
$$

where $\Delta \mathrm{S}^{\prime}$ is embankment settlement after considering the lateral deformation, $\Delta \mathrm{S}$ is embankment settlement without considering lateral deformation, and $\mathrm{S}^{\prime}$ is the embankment settlement difference influenced by the side.

\subsection{Calculation process}

To verify the correctness of the theory, the model test embankment settlement is calculated using the modified formula.

According to the calculation formula for soil compression and because the base of the new road overlaps the old embankment slope, if the layering calculation is performed, the thickness of each layer will be different. Therefore, the new embankment is divided into vertical and horizontal units. First, the soil settlement of each unit is calculated and then the superposition calculation is performed. The new divided embankment unit is shown in Fig. 9, where $\mathrm{L}=7.5 \mathrm{~cm}$ and $\mathrm{H}=7.5 \mathrm{~cm}$.

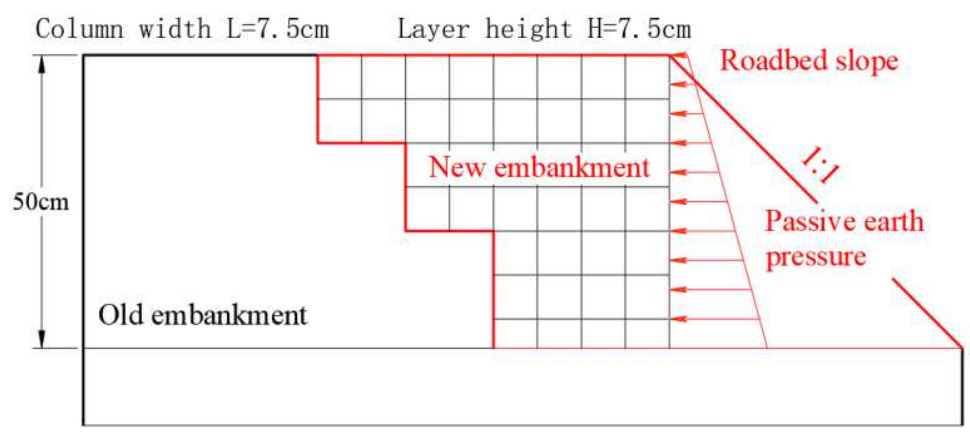

Fig. 9 Meshing.

According to the model test, the pavement load is converted to a uniform load. The calculation parameters are shown in Table 2.

Table 2 Calculation parameters.

\begin{tabular}{llll}
\hline Gravity $\left(\mathrm{kN} / \mathrm{m}^{3}\right)$ & $\operatorname{Load}(\mathrm{kPa})$ & Poisson's ratio & Internal friction angle $\left(^{\circ}\right)$ \\
\hline
\end{tabular}




\begin{tabular}{llll}
\hline 19 & 37 & 0.26 & 20 \\
\hline
\end{tabular}

The lateral deformation of soil is calculated according to the earth pressure value of each depth using the calculation method for stratified settlement. The calculated results are shown in Table 3.

Table 3 Calculation results.

\begin{tabular}{c|ccc|ccc}
\hline \multirow{2}{*}{ Layer } & \multicolumn{3}{|c|}{ Vertical deformation } & \multicolumn{3}{c}{ Lateral deformation } \\
& $e_{1 i}$ & $e_{2 i}$ & $\Delta S_{i}(\mathrm{~cm})$ & $e_{1 \mathrm{j}}$ & $e_{2 \mathrm{j}}$ & $S_{j}{ }_{j}(\mathrm{~cm})$ \\
\hline 1 & 0.987 & 0.749 & 8.98 & 0.987 & 0.865 & 4.60 \\
2 & 0.967 & 0.806 & 6.14 & 0.967 & 0.843 & 4.74 \\
3 & 0.952 & 0.881 & 2.73 & 0.952 & 0.829 & 4.73 \\
4 & 0.939 & 0.894 & 1.74 & 0.939 & 0.817 & 4.72 \\
5 & 0.931 & 0.905 & 1.01 & 0.931 & 0.81 & 4.70 \\
6 & 0.92 & 0.915 & 0.20 & 0.92 & 0.8 & 4.69 \\
\hline
\end{tabular}

According to Ma's expressions in [24], the mean value of $\mathrm{K}_{\mathrm{n}}$ is 0.16 in the long-term consolidation process. According to Equation 3, the settlement calculation formula of one point of the new embankment pavement as Equation 4:

$$
S_{\mathrm{j}}^{\prime}=\sum_{\mathrm{i}}^{6}\left(\frac{e_{1 i}-e_{2 i}}{1+e_{1 i}} L_{i}-K_{i j} v \frac{e_{1 j}^{\mathrm{H}}-e_{2 j}^{\mathrm{H}}}{1+e_{2 j}^{\mathrm{H}}} H_{i j}\right) \quad(j=1,2,3 \cdots 6)
$$

Two types of calculation results and model test results are shown in Fig. 10. From the deformation curve, at the sides of the new embankment slope, the embankment settlement is smaller than the deformation in the middle section of the new embankment, with an error of $6.2 \%$ compared with the test results. Compared with the existing settlement calculation method, the new calculation method can reduce the calculation error and the calculation process is simple.

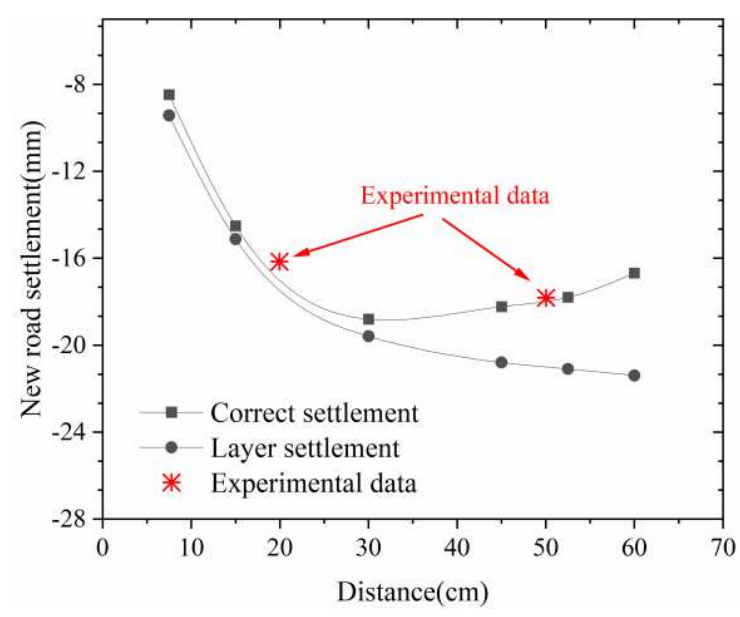

Fig. 10 Comparison of Settlement curve.

\section{Conclusion}

Aiming at the problem of differential settlement between the old and the new embankments, 
an embankment model test device is developed. Through the model test, the relationship between embankment settlement and lateral deformation is analyzed. Based on the onedimensional settlement calculation method, the lateral deformation coefficient $\mathrm{kn}$ is introduced to establish the two-dimensional settlement calculation method. The conclusion is as follows:

(1) The embankment test scheme designed in this paper can accurately perform the new and old embankment model tests, and the test data conform to actual engineering laws, which is a valuable reference for relevant research.

(2) Under the load of the new and old embankments, there is an obvious deformation in the interior and surface of the embankment. The lateral deformation of the embankment is in direct proportion to the vertical deformation. Under the condition of the ultimate load, the slope of the new embankment will slip and lose stability.

(3)The lateral deformation of the embankment is related to settlement and from the model test, and introduce the lateral deformation coefficient $\mathrm{Kn}$ based on the one-dimensional settlement calculation method. The two-dimensional settlement calculation method considering the lateral deformation improves the calculation accuracy of the new embankment settlement, and the error from the test result is $6.2 \%$.

\section{Acknowledgments}

This work was supported by the National Natural Science Foundation of China (No. 51778345, No.52078278), the Shandong Provincial Natural Science Foundation for Distinguished Young Scholars (No. JQ201811), the Key Research and Development Foundation of Shandong Province of China (No. 2019GSF109006), and the program of Qilu Young Scholars of Shandong University. Great appreciation goes to the editorial board and the reviewers of this paper.

\section{References}

Wang M, Cai GJ, Liu WY et al (2019) Evaluation of engineering characteristics of new and old soft soil foundation based on advanced CPTU data. Chinese Journal of Geotechnical Engineering 41(2): 81-84. https://doi.org/10.11779/CJGE2019S2021

Cui W, Lv GH, Liu CY (2017) Computational analysis of differential settlement on new subgrade in expressway widening, Science technology and engineering 17 (34):326-331. https://doi.org/10.3969/j.issn.1671-1815.2017.34.055

Sun, LQ, Yan SW, Xu Y (2011) Study of wave type asymmetry settlement and its mechanism of soft soil roadbed. Rock and Soil Mechanics 32(1): 526-531. https://doi.org/10.16285/j.rsm.2011.s1.090

Liu J, Jiang X, Qiu YJ (2015) Deformation Coupling Characteristics of Slope weak ground under Embankment Load. Journal of the China Railway Society 37:94-100. https://doi.org/10.3969/j.issn.1001-8360.2015.04.014

Reshma B, Rajagopal K, Viswanadham BVS (2020) Centrifuge model studies on the settlement response of geosynthetic piled embankments. Geosynthetics International 27:170-181. https://doi.org/10.1680/jgein.19.00009

Wu PC, Feng WQ, Yin JH (2020) Numerical study of creep effects on settlements and load transfer mechanisms of soft soil improved by deep cement mixed soil columns under embankment load. Geotextiles and Geomembranes 48:331-348. https://doi.org/10.1016/j.geotexmem.2019.12.005

Liu GX, Li YG, Cao YN (2018) Calculation and analysis of lateral deformation of ground under embankment load. Rock and Soil Mechanics 39:4517-4536. https://doi.org/10.16285/j.rsm.2017.1045

Chai CY, Zhang GG, Wu XY (2017) Analysis of the Influence of Lateral Deformation of Soft Soil 
Embankment on Nearby Building Foundation. Journal of Railway Engineering Society 34:23-26+31. https://doi.org/ 10.3969/j.issn.1006-2106.2017.06.005

Li GW, Jiang HZ, Yang T, Sheng WG (2008) Influence of lateral deformation on settlement of thick soft soil underlying embankment. Rock and Soil Mechanics 29(10):2817-2822. https://doi.org/ 10.16285/j.rsm.2008.10.017

Fang L, Zhu ZG (2005) Study of influence factors of lateral deformation of soft soil foundation under embankments. Highway and Transportation Science and Technology 11:38-42. https://doi.org/ 10.3969/j.issn.1002-0268.2005.11.009

Tavenas F, Mieussens, C, Bourges, F (1979) Lateral displacements in clay foundations under embankments. Canadian Geotechnical Journal 16:532-550. https://doi.org/10.1139/t79-059

Indraratna B., Balasubramaniam, A.S., and Sivaneswaran, N. (1997). Analysis of settlement and lateral deformation of soft clay foundation beneath two full-scale embankments. International Journal for Numerical and Analytical Methods in Geomechanics 21(9):599-618. https://doi.org/ 10.1002/(SICI)1096-9853(199709)21:93.0.CO;2-L

Pan GF, Liu XF, Yuan SY, Sun DX et al (2020) Lateral deformation of embankment with the CFG pilenet structure for Yun-Gui passenger dedicated line. Rock and Soil Mechanics, 41(2):1-11. https://doi.org/10.16285/j.rsm.2020.0126

Loganatfian N, Balasubramaniam A S, Bergado D T (1993) Deformation analysis of embankments[J]. Journal of Geotechnical Engineering 119(8): 1185-1206. https://doi.org/10.1061/(ASCE)07339410(1993)119:8(1185)

Han JL, Zhao Y (2012) Analysis on the settlement characteristics of lateral displacement of the high embankments. Journal of Wuhan University of Technology(Transportation Science and Engineering) 36, 165-167. https://doi.org/10.3963/j.issn.1006-2823.2012.01.039

Jiang GL, Lan WW, Xiao HB, Chen WZ (2014) Calculation method for lateral deformation of foundation under subgrade load. Journal of Chongqing University 37(2):89-97.

Giroud JP, Nhiem TV, Obin JP. Mecanique des sols-tables pour le calcul des fondations[EB/OL]. http://worldcat.org/isbn/2040073493. 2012- 09-24.

Ma S (1995) Lateral displacement of soft clay foundation under embankment. Journal of Huaqiao University (Natural Science Edition) 16(02):165-167. 
Figures

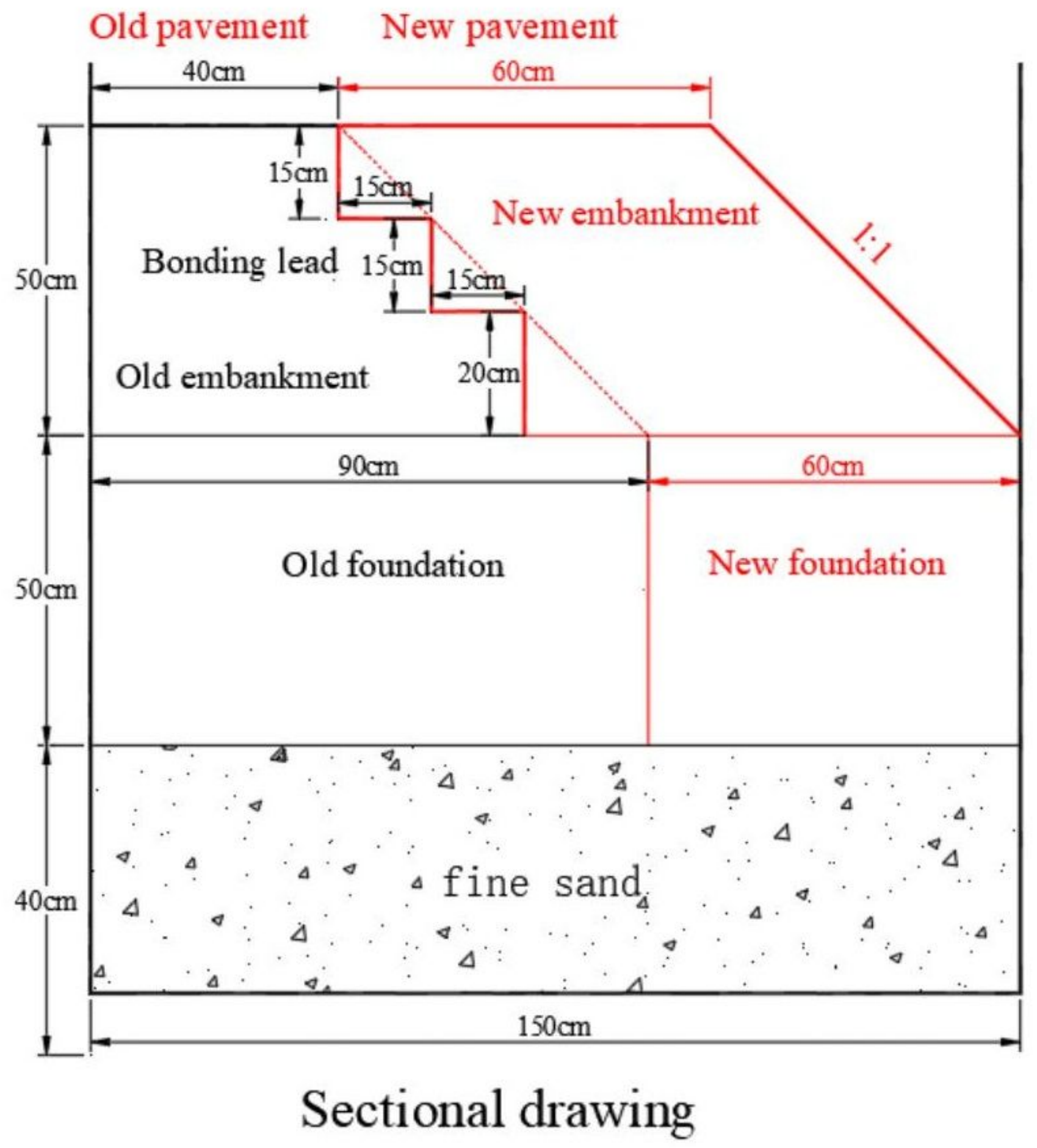

Figure 1

Model size chart. 

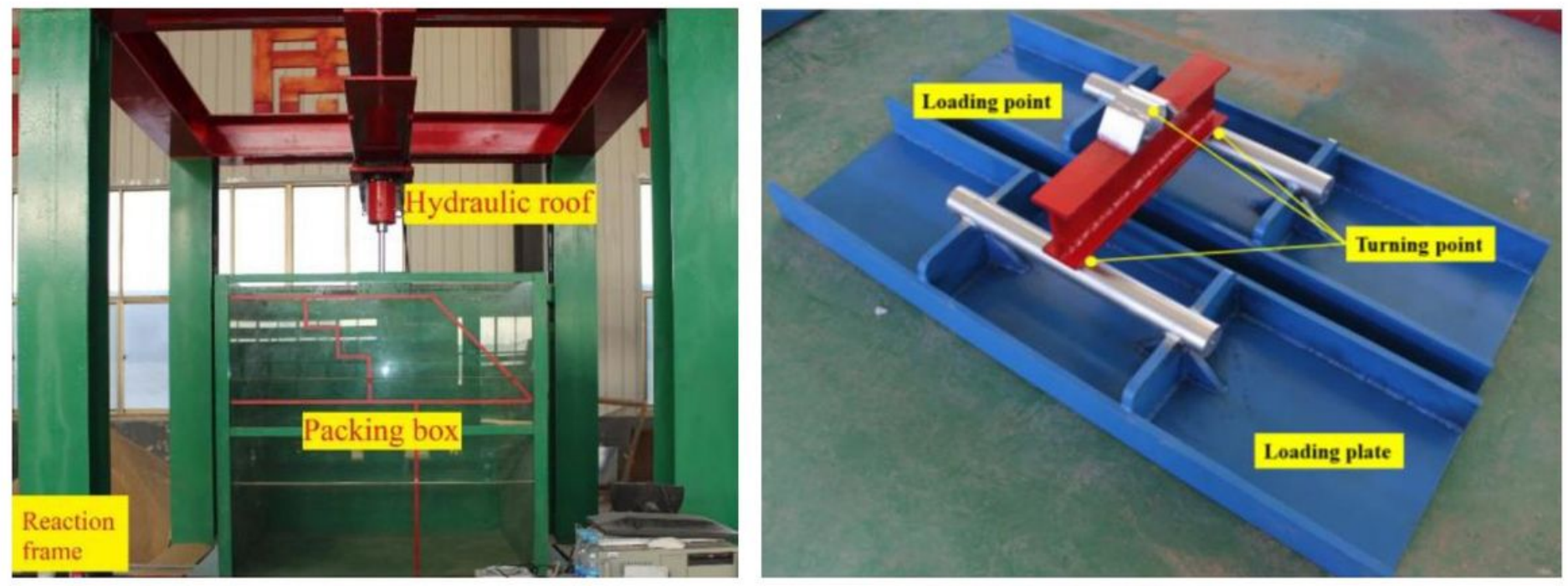

\section{Figure 2}

The test device. (a) Test stand. (b) Road loading device.
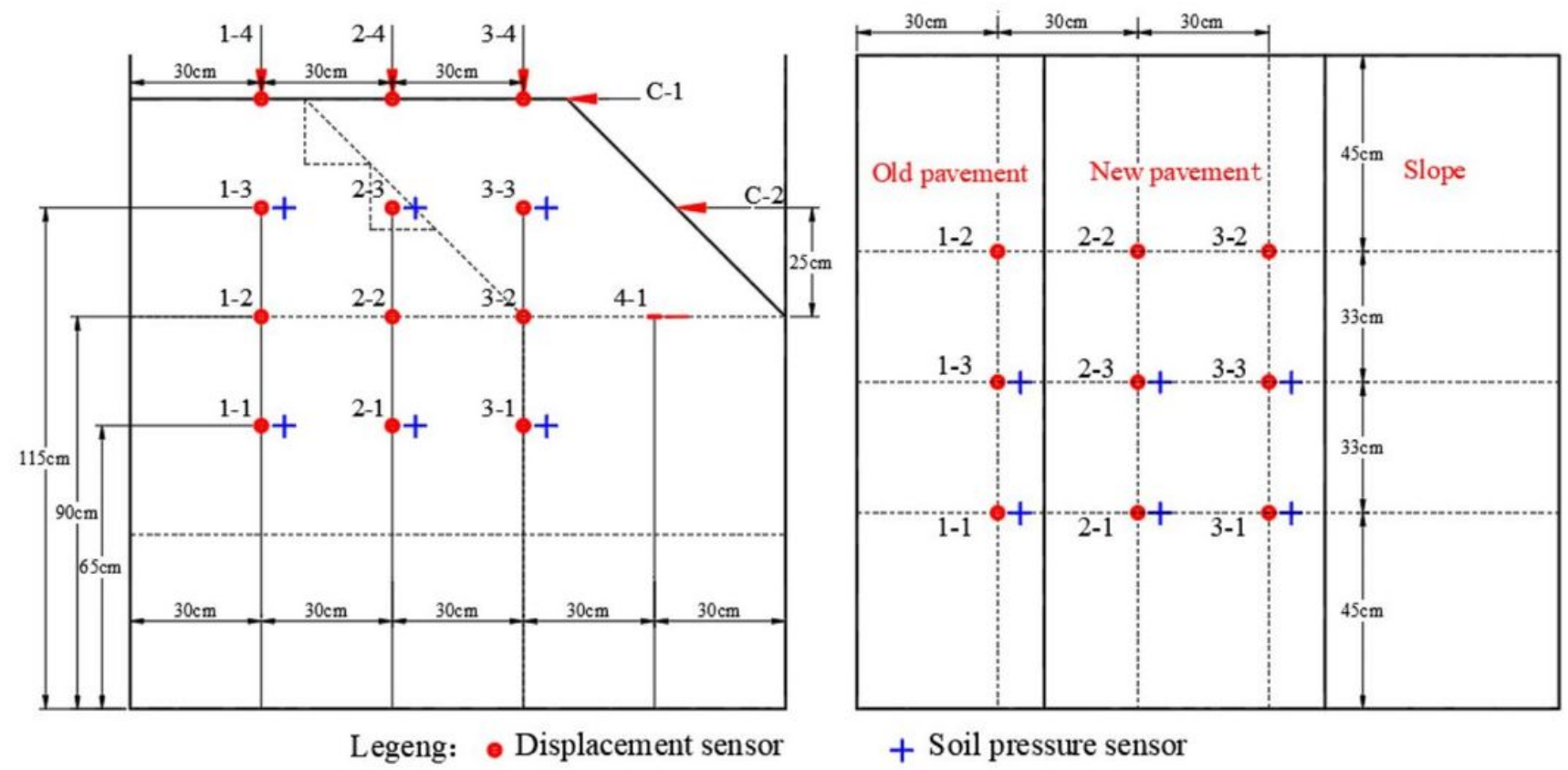

+ Soil pressure sensor

Figure 3

Monitoring point layout. 


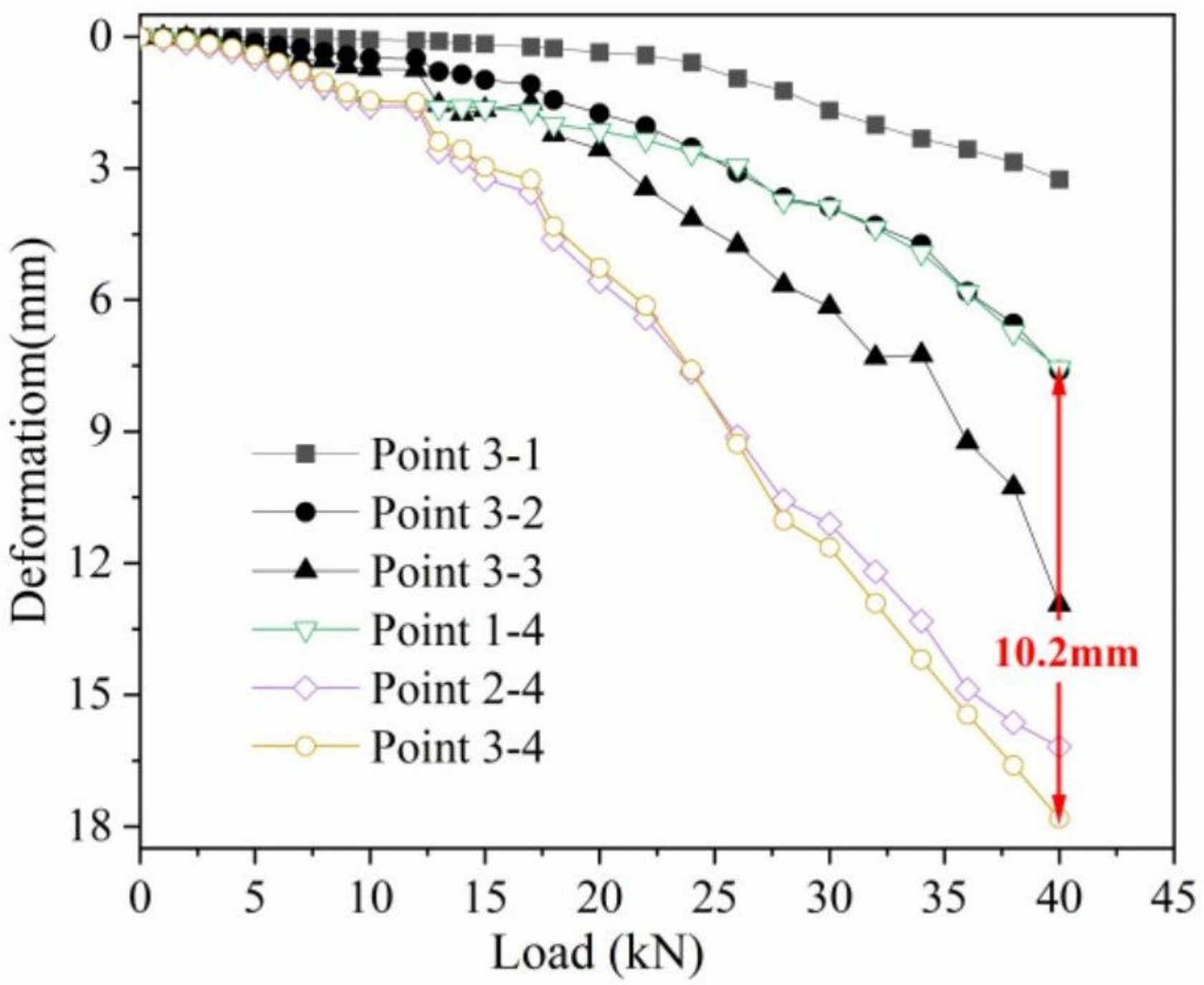

Figure 4

Settlement of the embankment. 


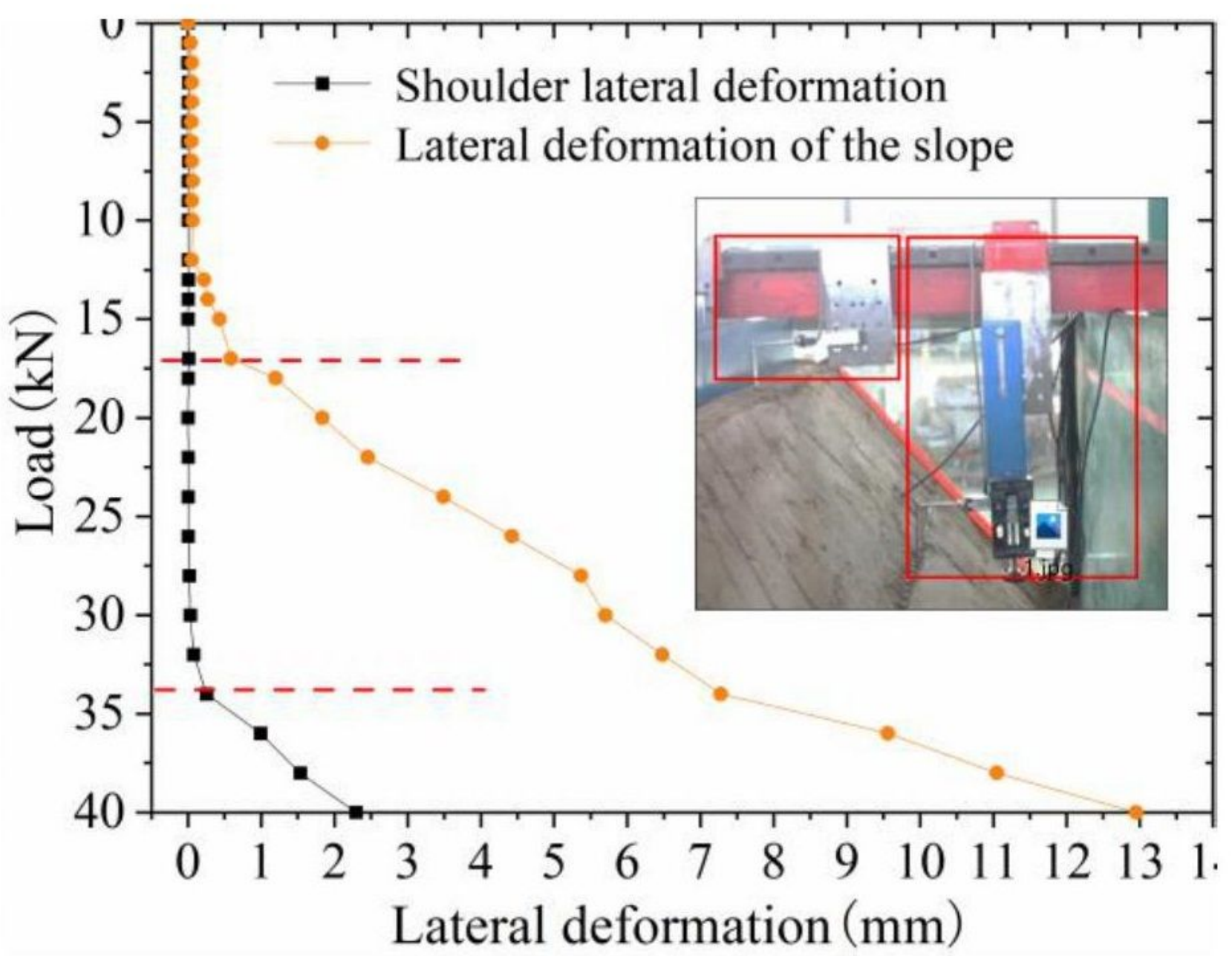

Figure 5

Lateral deformation. 


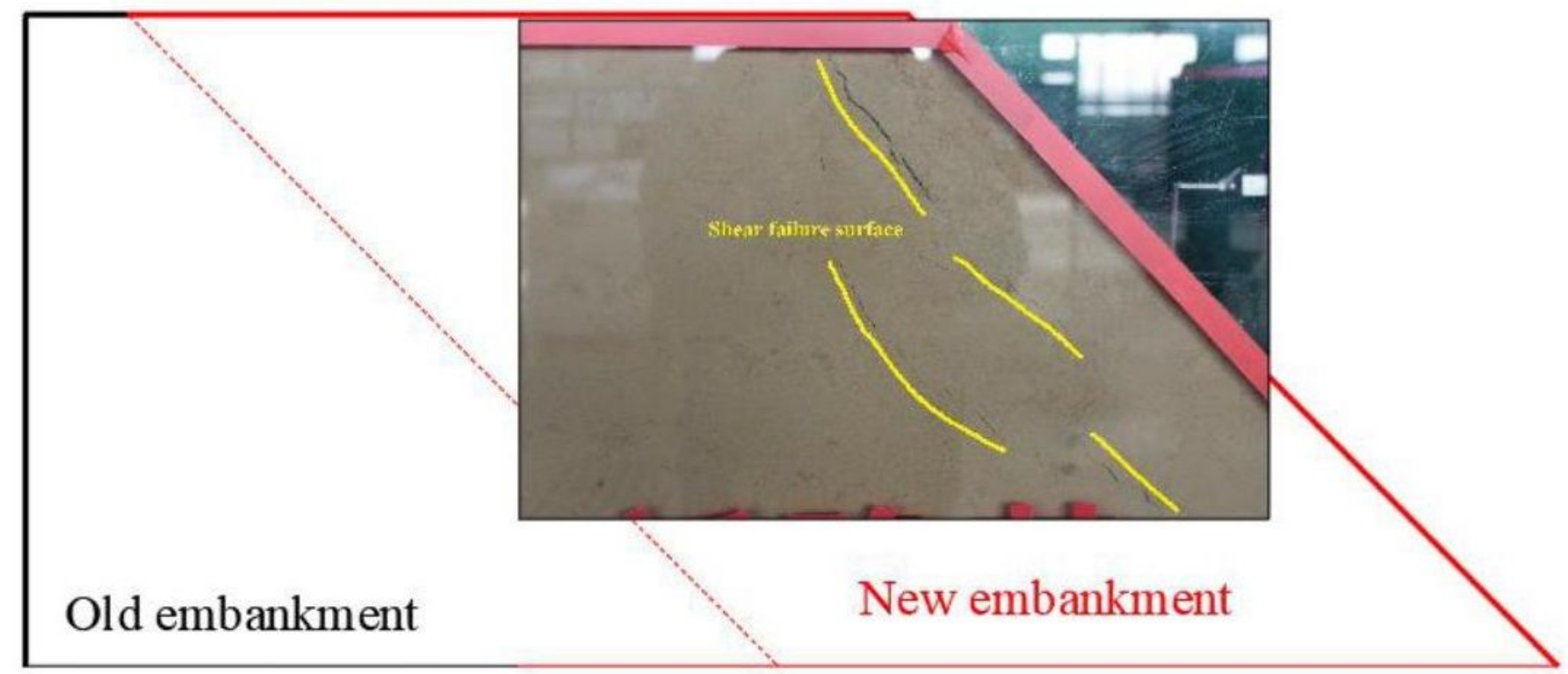

Figure 6

The failure mode of the new embankment. 


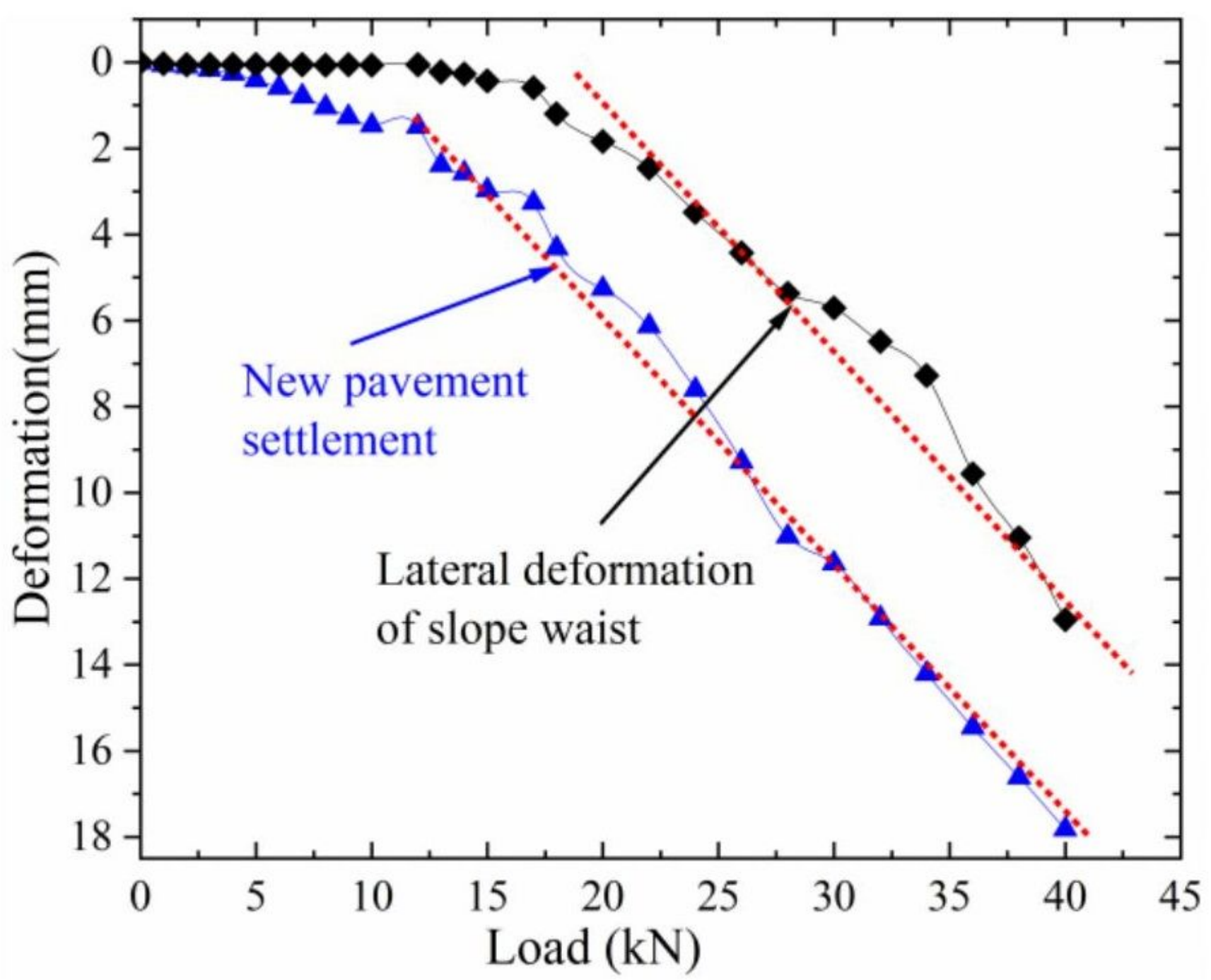

Figure 7

The deformation relation.

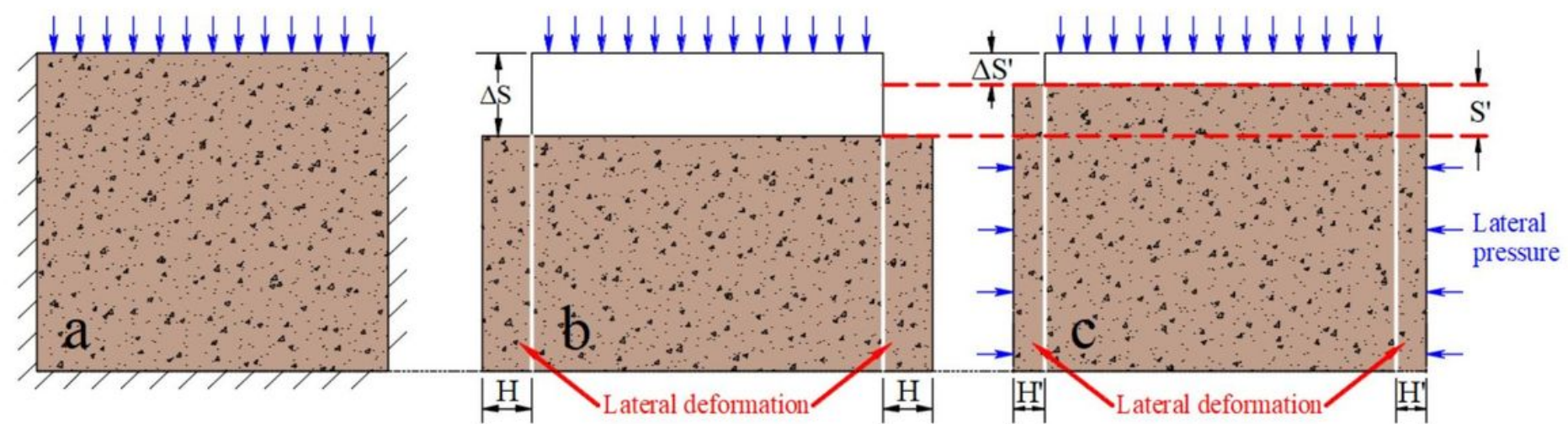

Figure 8 
Calculation model. (a) soil unit. (b) No lateral pressure deformation. (c) With lateral pressure deformation.

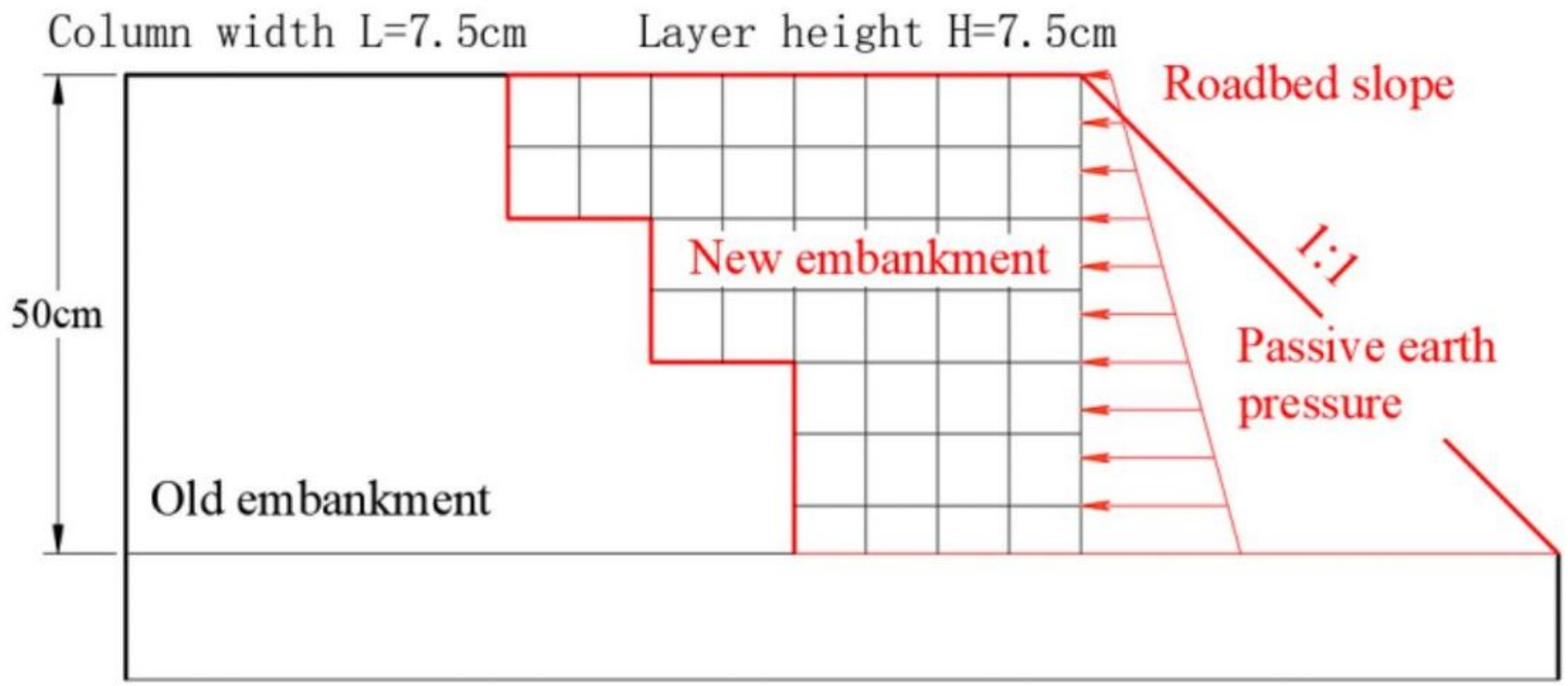

Figure 9

Meshing. 


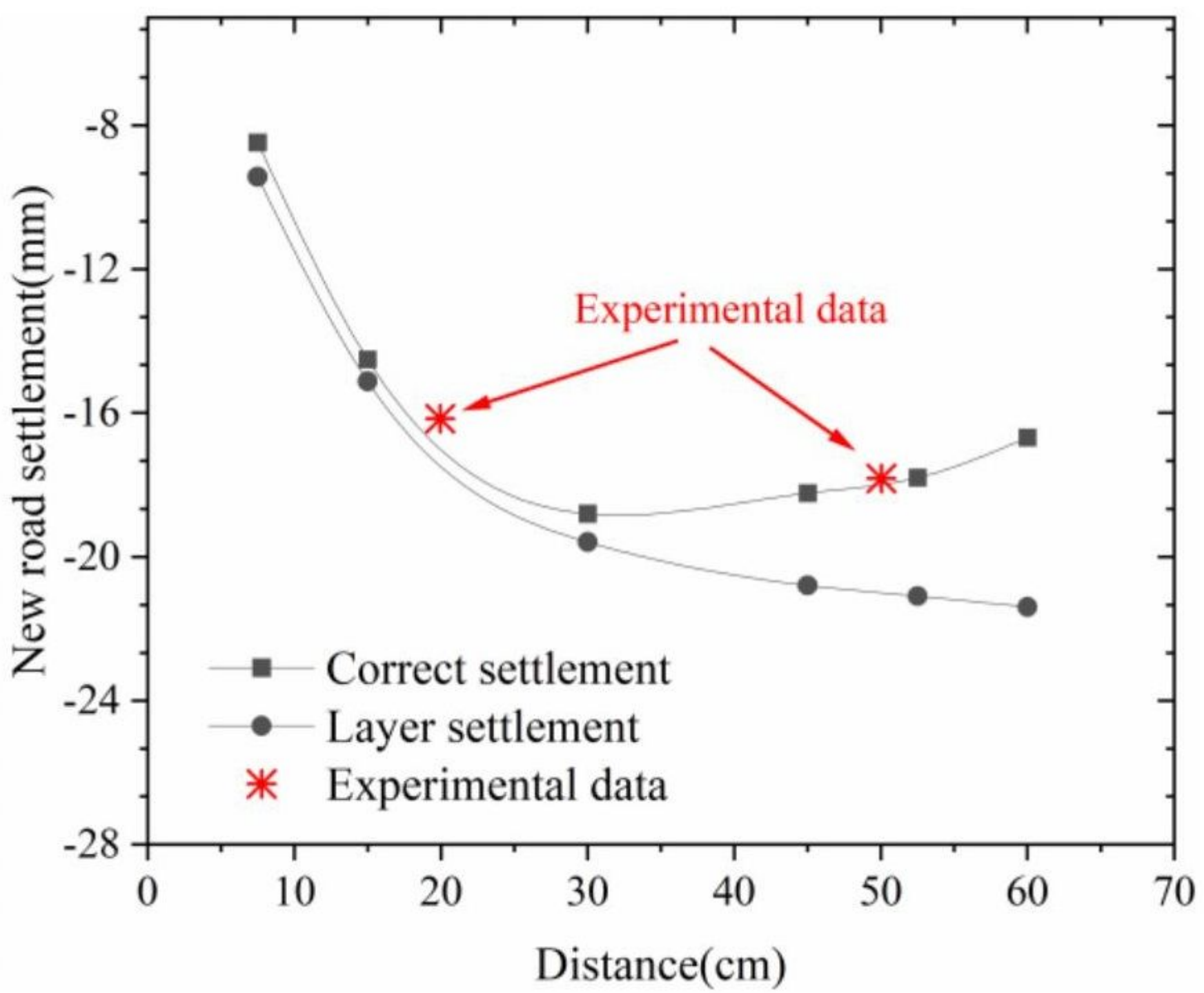

Figure 10

Comparison of Settlement curve. 